mean live weight of $32 \mathrm{~kg}$ were kept in individual pens and received only cereal based diets $(97$ p. 100 oats). They were subjected to a 10 -days faeces collection period. Three types of oats were tested : two regular oats (black and white) and one batch of naked oats containing $15.0,11.8$ and 2.9 p. 100 crude fibre respectively, on a dry matter basis.

An increase in the crude fibre content led to a highly significant linear decrease in the apparent digestibility of energy (ADE) according the following relationships :

$$
\begin{aligned}
& \mathrm{ADE}=92.14-2.02 \mathrm{CF} \text { p. } 100 \mathrm{DM}\left(\mathrm{r}=-0.994^{* *}, \mathrm{CV}_{\mathrm{r}}=1.7\right. \text { p. 100) } \\
& \mathrm{ADE}=91.85-1.76 \mathrm{ADF} \text { p. } 100 \mathrm{DM}\left(\mathrm{r}=-0.995^{* *}, \mathrm{CV}_{\mathrm{r}}=1.6\right. \text { p. 100) } \\
& \mathrm{ADE}=93.88-0.91 \mathrm{NDF} \text { p. } 100 \mathrm{DM}\left(\mathrm{r}=-0.990^{* *}, \mathrm{CV}_{\mathrm{r}}=2.2\right. \text { p. 100) }
\end{aligned}
$$

The results showed that the energy value (DE) of oats was closely related to the cell wall content. The curde fibre content (Weende) semmed to be the main factor affecting the feeding value of oats for pigs, since it accounted for 99 p. 100 of the variation in DE content. It is possible to predict the digestible energy value of oats using a correction of $90 \mathrm{Kcal}$ per supplementary point of crude fibre in the seed dry matter :

$$
\begin{gathered}
\mathrm{DE}(\mathrm{Kcal} / \mathrm{kg} \mathrm{DM})=4230-90 \mathrm{CF} \text { p. } 100 \mathrm{DM} \\
\left(\mathrm{r}=-0.995^{* * *}, \mathrm{CV}_{\mathrm{r}}=1.5 \text { p. } 100\right)
\end{gathered}
$$

\title{
Utilization of moist grain maize silage in the bacon pig Effect of the moisture content and of the presence of cobs
}

\author{
J. CASTAING, R. COUDURE, F. GROSJEAN * \\ A.G.P.M., 122, boulevard Tourasse, 64000 Pau \\ * I.T.C.F., 8, avenue dlu Président-Wilson, 75116 Paris \\ France
}

Four experiments were made to study the effect of the moisture content of grain at harvesting on the feeding value of maize silage containing only grain and to determine the feeding value of silage resulting from the mixture of grain with cob.

\section{Effect of the moisture content of maize at harvesting}

When grain was harvested with a moisture content of 41 or 37 p. 100 then ground and silaged it was preserved very well. Utilization of both silages led to very similar growth rates, feed efficiency and carcass performance. It was concluded that the D.M. feeding value of dry or silaged maize grain was equivalent.

When harvested with a moisture content of 24 p. 100, the maize quality decreased after opening of the silo and its feeding value was considerably reduced.

\section{Effect of the presence of $80 \mathrm{p} .100$ of the ear cobs}

Two maize silages including cobs were studied in three trials. They contained 39 and 35 p. 100 moisture and 4.5 and 3.8 p. 100 crude fibre, respectively.

In each trial, silage of «maize + cobs » was compared to silage of grain alone with the same moisture content. Replacement of moist maize grain by "maize + cobs » was made on the basis of the same dry matter content. Accordingly, the presence of cobs reduced the energy concentration of the diet.

The lower energy intake with maize silage + cobs compared to maize alone led to a decrease in the growth rate of pigs, to a deterioration of the feed conversion ratio (by 2.4 , 5.4 and 7.5 p. 100 according to the trial) and to an improvement in the carcass quality. The carcass yield was reduced by the presence of cobs in one trial out of three (by 0.8 point). According to these results, the feeding value of maize silage + cobs ranged between 90 and 97 p. 100 that of maize grain alone on a dry matter basis. This seems more favourable than the first results published in the literature. 